\title{
Sobre a poesia de Homero e sobre Virgílio, de William Blake
}

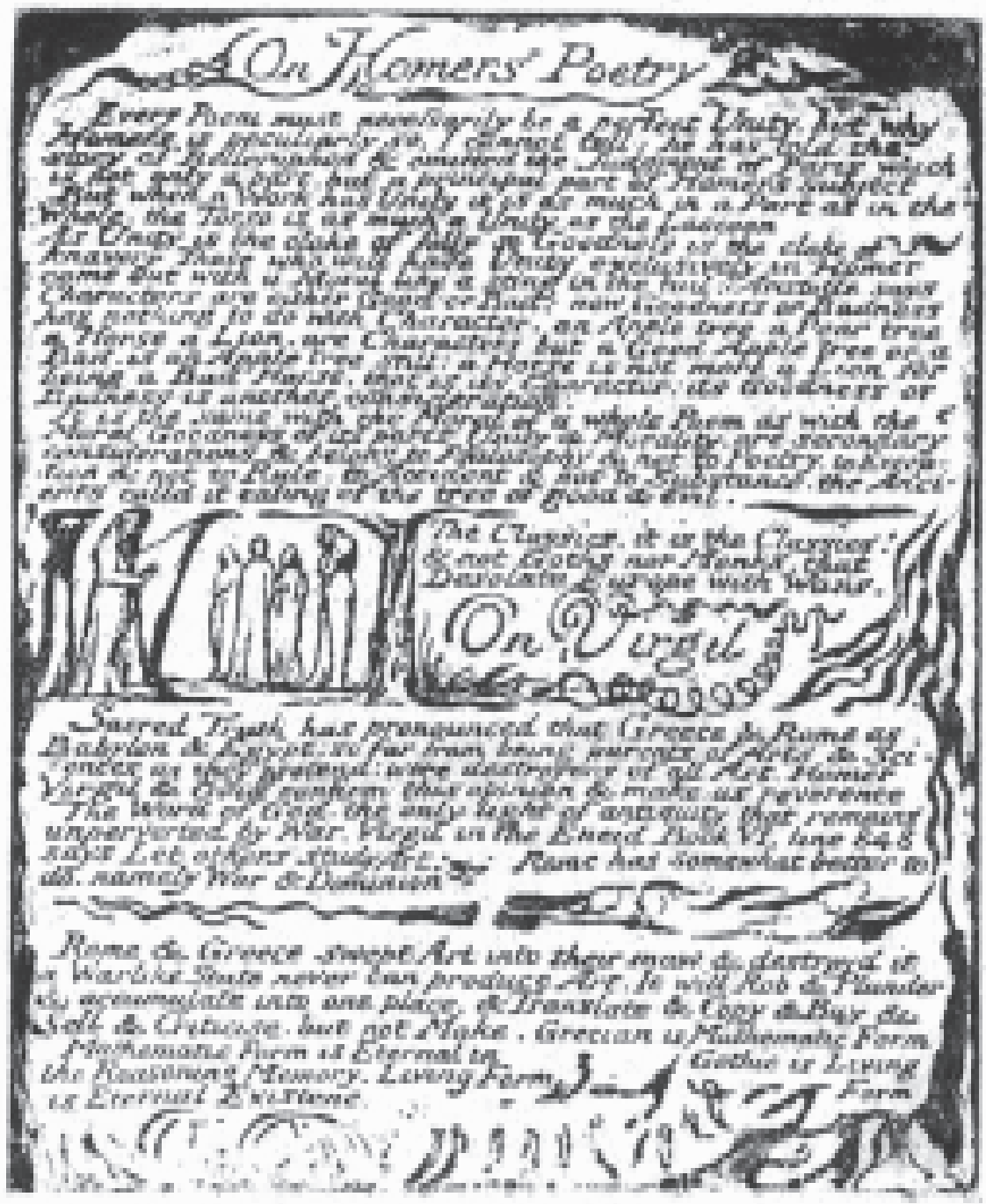


Juliana Steil. Sobre a poesia de Homero e sobre Virgílio, de William Blake

\section{Fragmento de obra aberta}

A crítica recente tem defendido que a obra de Blake é uma obra aberta, em contraposição à tendência mais tradicional que a considera um sistema fechado de símbolos estáveis. As imagens recorrentes de um livro a outro, nesse caso, iriam assumindo novos significados a cada contexto, ampliando e somando sentidos ao conjunto.

A condição de obra "aberta", contudo, não significa que o corpus blakiano possa suportar leituras ilimitadas. Em vez disso, ela reconhece níveis de leitura sobrepostos em uma cadeia de discursos interligados, operando em uma discussão ao mesmo tempo religiosa, política, econômica, filosófica, conceitual e material (MAKDISI, 2003: 75). Assim, On Homers Poetry [and] On Virgil ${ }^{1}$ apresenta outras questões além dos problemas de teoria literária evidentes à primeira leitura destes tratados.

Em On Homers Poetry, Blake não está apenas criticando a aplicação de conceitos lógico-racionais - como a "unidade da estrutura" e a "moral das personagens", por exemplo - à poesia homérica e à poesia em geral; o poeta refere-se, ao mesmo tempo, a uma forma de pensamento que, para ele, influenciaria a era industrial, levando a uma visão da sociedade como um grande corpo coletivo no qual os indivíduos seriam membros trabalhando para a produção de um objeto comum. Nesse sentido, a existência de modelos estabelecidos estaria relacionada às ideias de controle, disciplina e dominação.

Da mesma forma, a opinião blakiana sobre o tema bélico na literatura da antiguidade clássica não é tudo o que expressa On Virgil. Ao valorizar a cultura do Oriente em detrimento da cultura ocidental - exatamente o inverso do discurso revolucionário do seu tempo, que, como uma espécie de estratégia para a consolidação de seus princípios políticos, procurava enfatizar a separação entre Ocidente e Oriente, inferiorizando o último - o texto blakiano contesta os con-

Desta gravura, produzida por volta de 1820, seis são as cópias que se conservam até hoje. 
ceitos predominantes na época. Esse gesto de contrabalançar diferenças vem da fé em uma humanidade original que teria tido uma única língua e uma única religião. A aceitação de um Gênio Poético comum à infinita variedade de seres humanos, para Blake, é incompatível com qualquer modelo de sociedade que tenha por base a hierarquização de sujeitos.

As questões enumeradas aqui apontam apenas algumas das possibilidades e níveis de leitura de On Homers Poetry [and] On Virgil, um texto que certamente mostra um pouco das características narrativas que têm justificado o fascínio que vem sendo atribuído à obra de William Blake.

\section{Breve comentário sobre nossa tradução de On Homers Poetry [and] On Virgil}

A tradução destes dois breves tratados não deixa de oferecer suas complicações. A principal delas cai em torno do termo "Character" (linhas 11, 12, 13 e 15), cujo sentido abre-se para várias opções lexicais em língua portuguesa. Para uma solução satisfatória, o contexto exigiu a consideração da fonte citada.

No referido trecho de On Homers Poetry, há uma referência à opinião aristotélica de que o traço distintivo da personagem se classifica em bom ou mau:

No que diz respeito aos caracteres, há quatro aspectos que se devem ter em vista, e o primeiro e mais importante é que os caracteres sejam bons. Haverá carácter se, como se disse, as palavras ou as acções da personagem mostrarem que está animada de um certo propósito, e o carácter será bom se esse propósito for bom. [...] (Poética, cap. XV - Aristóteles, 2004: 67).

A edição crítica da Poética preparada por Ana Maria Valente traz "carácter" como tradução de "ethos". A justificativa da tradução aparece na nota de rodapé número 71: Conforme Lucas, 1968: 
Juliana Steil. Sobre a poesia de Homero e sobre Virgílio, de William Blake

157, ethos (ท́⿴囗十) ) tanto parece significar uma dramatis personae como o carácter de uma personagem. Em ambos os sentidos, mantemos a tradução 'carácter'" (in: ARISTÓTELES, 2004: 67). Acreditando na correspondência entre ethos de Aristóteles e Character de Blake, adotamos a decisão da tradutora portuguesa e, ao usar "caráter", preferimos fazer nossa tradução concordar com esta e com as três outras traduções da Poética em língua portuguesa consultadas (ARISTÓTELES, 1997; s/d; 2004b).

Outras escolhas da nossa tradução foram feitas em favor do ritmo e do estilo do autor:

Um Pé de Maçã, um Pé de Pera, um Cavalo, um Leão, são Caracteres; mas o Pé de Maçã sendo Bom ou Mau, ainda é Pé de Maçã.

[an Apple tree a Pear tree a Horse a Lion. are Characters but a Good Apple tree or a Bad, is an Apple tree still:]

Além de favorecerem o ritmo da linha, as traduções "Pé de Maçã" e "Pé de Pera", inclinadas ao coloquial da língua, contribuem, a nosso ver, para a recomposição da ironia do original no texto traduzido.

As maiúsculas estrategicamente distribuídas no texto original foram mantidas na tradução; porém, não procedemos da mesma forma com outra das marcas do estilo blakiano, que é a pontuação não-convencional. Nesta tradução, experimentamos fazer algumas adequações na pontuação.

\section{On Homers Poetry [and] On Virgil, copy F}

02 Every Poem must necessarily be a perfect Unity. but why

03 Homers is peculiarly so, I cannot tell: he has told the

04 story of Bellerophon \& omitted the Judgment of Paris which 
05 is not only a part, but a principal part of Homers subject

06 But when a Work has Unity it is as much in a Part as in the

07 Whole. the Torso is as much a Unity as the Laocoon

08 As Unity is the cloke of folly so Goodness is the cloke of

09 knavery Those who will have Unity exclusively in Homer

10 come out with a Moral like a sting in the tail: Aristotle says

11 Characters are either Good or Bad: now Goodness or Badness

12 has nothing to do with Character. an Apple tree a Pear tree

13 a Horse a Lion. are Characters but a Good Apple tree or a

$14 \mathrm{Bad}$, is an Apple tree still: a Horse is not more a Lion for

15 being a Bad Horse, that is its Character; its Goodness or

16 Badness is another consideration.

17 It is the same with the Moral of a whole Poem as with the

18 Moral Goodness of its parts Unity \& Morality. are secondary

19 considerations \& belong to Philosophy \& not to Poetry. to Excep-

20 -tion \& not to Rule. to Accident \& not to Substance, the Anci-

21 ents calld it eating of the tree of good \& evil.

34 Rome \& Greece swept Art into their maw \& destroyd it 35 a Warlike State never can produce Art. It will Rob \& Plunder

The Classics, it is the Classics! \& not Goths nor Monks, that Desolate Europe with Wars.

\section{On Virgil}

Sacred Truth has pronounced that Greece \& Rome as Babylon \& Egypt: so far from being parents of Arts \& Sci-ences as they pretend: were destroyers of all Art. Homer Virgil \& Ovid confirm this opinion \& make us reverence The Word of God. the only light of antiquity that remains unperverted by War. Virgil in the Eneid Book VI. line 848 says Let others study Art; Rome has somewhat better to do. namely War \& Dominion 
Juliana Steil. Sobre a poesia de Homero e sobre Virgílio, de William Blake

36 \& accumulate into one place, \& Translate \& Copy \& Buy \&

37 Sell \& Criticise. but not Make. Grecian is Mathematic Form

38 Mathematic Form is Eternal in Gothic is Living

39 the Reasoning Memory. Living Form Form

40 is Eternal Existenc

\section{Sobre a Poesia de Homero e Sobre Virgílio}

02 Todo Poema deve necessariamente ser uma Unidade perfeita. Mas por que

03 o de Homero é peculiarmente assim, não sei dizer: ele contou

04 a história de Belerofonte \& omitiu o Julgamento de Paris, que

05 não só é uma parte, mas uma parte fundamental do tema de Homero.

06 Mas quando uma Obra tem Unidade, é tanto numa Parte como no

07 Todo. O Torso é tanto uma Unidade quanto o Laocoonte.

08 Assim como a Unidade é o manto da tolice, a Bondade é o manto da

09 canalhice. Aqueles que vão buscar Unidade exclusivamente em Homero

10 acabam voltando com a Moral tosquiada: diz Aristóteles

11 que Caracteres são ou Bons ou Maus. Ora, Bondade ou Maldade

12 nada têm a ver com Caráter: Um Pé de Maçã, um Pé de Pera,

13 um Cavalo, um Leão, são Caracteres; mas o Pé de Maçã sendo Bom

14 ou Mau, ainda é Pé de Maçã. Um Cavalo não se torna um Leão por

15 ser um Cavalo Mau, aquele é seu Caráter; sua Bondade ou

16 Maldade é outra consideração.

17 É o mesmo com a Moral de um Poema inteiro ou com

18 a Bondade Moral de suas partes. Unidade \& Moralidade são considerações

19 secundárias \& pertencem à Filosofia \& não à Poesia, à Exce-

20 ção \& não à Regra, ao Acidente \& não à Substância. Os An-

21 tigos chamaram isto comer da árvore do bem \& do mal.

Os Clássicos, são os Clássicos! 
26 A Verdade Sagrada declarou que Grécia \& Roma, como

27 Babilônia \& Egito, longe de serem os pais das Artes \& Ci-

28 ências como se dizem, foram destruidores de toda Arte. Homero,

29 Virgílio \& Ovídio confirmam esta opinião e fazem-nos reverenciar

30 A Palavra de Deus, única luz da Antigüidade que permanece

31 incorrupta pela Guerra. Virgílio, na Eneida, Livro VI, verso 848, diz:

32 Deixai outros estudarem Arte; Roma tem coisa melhor a

33 fazer, isto é: Guerra \& Dominação.

34 Roma \& Grécia dragaram a Arte para dentro de suas panças \& a destruíram.

35 Um Estado Marcial jamais pode produzir Arte. Pode Roubar \& Pilhar

36 \& acumular de um lado; \& Traduzir \& Copiar \& Comprar \&

37 Vender \& Criticar. Mas não Produzir. A Arte Grega é Forma Matemática.

38 Forma Matemática é Eterna na Memória Racional.

39 A Arte Gótica é Forma Vivente.

40 Forma Vivente é Existência Eterna.

\section{Referências}

\section{Do original (gravura e transcrição textual):}

BLAKE, William. On Homers Poetry [and] On Virgil, copy F (Pierpont Morgan Library). The William Blake Archive. Ed. Morris Eaves, Robert N. Essick, and Joseph Viscomi. 29 June 2007 <http://www.blakearchive.org/>.

\section{Dos comentários:}

ARISTÓTELES, HORÁCIO, LONGINO. A poética clássica. Tradução de Jaime Bruna. 7aㅡ ed. São Paulo: Cultrix, 1997.

ARISTÓTELES. Arte Poética e Arte Retórica. Tradução de Antônio Pinto de Carvalho. 16 $6^{\underline{a}}$ ed. São Paulo/Rio de Janeiro: Ediouro, sem data. 
Juliana Steil. Sobre a poesia de Homero e sobre Virgílio, de William Blake

Poética. Tradução de Ana Maria Valente. Lisboa: Fundação Calouste Gulbenkian, 2004.

"Poética". Tradução de Baby Abrão. In: Poética, Organon, Política, Constituição de Atenas. Coleção Os Pensadores. São Paulo: Nova Cultural, $2004 b$.

MAKDISI, Saree. William Blake and the Impossible History of the 1790s. Chicago / London: The University of Chicago Press, 2003. 